\title{
Prevalence of Urinary Incontinence according to its type (Stress, Urge Or Mixed) in females and its association with age and parity: A hospital based study
}

\author{
Sangeeta Jain $^{1^{*}}$, Shishir Mathur ${ }^{2}$, Prasoon Choudhary ${ }^{3}$ \\ and Sarita Choudhary ${ }^{4}$
}

${ }^{1}$ Assistant professor, Department of Anatomy

${ }^{2}$ Professor, Department of Physiology

${ }^{3}$ Professor, Department of Anatomy

${ }^{4} \mathrm{UG}$ scholar (Internee)

Homoeopathy University, Saipura, Sanganer,

Jaipur, Rajasthan, India

\begin{abstract}
Urinary incontinence is one of the priority health issue recognized by World Health Organisation. Urinary incontinence is defined as "a condition in which involuntary loss of urine is objectively demonstrable." The present hospital-based crosssectional study was conducted from November 2018 to January 2019. Total 322 women aged above 18 years were screened, who attended the hospital OPD of Homoeopathy University, Saipura, Sanganer, Jaipur. They were subjected to set of questionnaire related to urinary incontinence. Among the 322 participants the prevalence of urinary incontinence was $55.3 \%$ (95\% confidence interval: $0.50-0.60 \%$ ). The most common subtype was stress incontinence followed by mixed incontinence. The adjusted analysis revealed that women with middle age group (33-48 years) had more incidence of urinary incontinence $(p \quad$ value $=0.000 ; \quad \chi 2=60.802)$ and urinary incontinence showed an increasing trend with increasing parity with the $p$ value $=0.002$ $(\chi 2=9.297)$.
\end{abstract}

Key words: Prevalence, urinary incontinence, stress urinary incontinence, age and parity.

\section{INTRODUCTION}

Urinary incontinence (UI) is defined by the international continence society as an "involuntary loss of urine which is objectively a demonstrable, social and hygienic problem." This is a common problem with widespread human and social implications causing discomfort, shame, and loss of self-confidence. ${ }^{2}$

UI is three times more common in females than in males. ${ }^{3}$ One out of five women in the world suffers from the urinary incontinence. ${ }^{4}$ A survey of Asian countries showed variation in prevalence of UI but confirmed that the condition affects individuals throughout the region. ${ }^{5}$ UI can be considered as a normal part of aging when in fact it's not and is observed in women at any age group from different cultures and races, contrary to general opinion which is more common in elderly population, thus constituting a worldwide problem. ${ }^{6,7,8}$

Urinary incontinence is regarded as a disgraceful situation, with a negative effect on quality of life (QOL) and is usually kept disguised; it is an important disease leading to physical, social, psychological and sexual problems among women of all age groups. ${ }^{9}$ Though urinary incontinence is not life-threatening; it is a very debilitating condition. There appears to be a stigma attached to urinary incontinence that causes one to suffer in silence. There is general misconception that urinary incontinence is an inevitable consequence of aging and that they will have to live with it for the rest of their lives. Patients fear that they are losing control over their bodily functions and there is nothing they can do about it. This feeling of helplessness leads to significant levels of depression, especially in women with urinary incontinence. ${ }^{10}$ 
The objectives of the present cross-sectional study were to know the prevalence of urinary incontinence according to its types, age and parity of women above 18 years of age. This study is a sincere attempt to enhance awareness in females related to their continence status so that necessary steps in its prevention and treatment can be taken to improve the quality of life of females as they are very important part of our society and giving birth to new lives.

\section{REVIEW OF LITERATURE}

According to medical definition the urinary incontinence is the unintentional loss of urine; inability to hold urine in the bladder due to loss of voluntary control over the urinary sphincters resulting in the involuntary passage of urine. ${ }^{11}$

Classification:

Based on etiology and pathophysiology, urinary incontinence is classified into three types ${ }^{10}$ -

Stress urinary incontinence (SUI): It is defined by the international Urogynecological association and international continence society as "complaint of involuntary loss of urine on effort or physical exertion (e.g. sporting activities), or on sneezing or coughing." 12

Urge Urinary Incontinence (UUI): It is defined as involuntary leakage of urine accompanied by or immediately preceded by urgency. This is most common form of incontinence in older women. ${ }^{13}$

Mixed Urinary Incontinence (MI): It is the involuntary leakage of urine associated with exertion and urgency. It includes mixture of both stress and urge urinary incontinence. It is also common in older women. $^{14}$

\section{ETIOPATHOGENESIS:}

Stress urinary incontinence (SUI): Stress urinary incontinence, also known as effort incontinence, is due essentially to insufficient strength of the pelvic floor muscles and caused by loss of support of the urethra. ${ }^{15}$ An increase in abdominal pressure due to physical exertion places stress on the bladder, causing urine to leak. The basic mechanisms of failure of the urethra to maintain a water-tight seal are poor urethral support by the pelvic floor muscles and intrinsic sphincter deficiency. Some of the main etiologic factors for SUI include ${ }^{10}$ :-

1. Anatomic and neurological injury to the pelvic floor during childbirth.

2. Genetic susceptibility or predisposition to having poor tissue strength can be considered a contributing factor.

3. Individual behavioral aspects such as smoking, obesity, alcohol consumption, excessive liquid intake, caffeine consumption, and rigorous exercise can be factors leading to SUI.

4. Medical conditions such as chronic obstructive pulmonary disease, estrogen deficiency, and aging may be considered confounding factors for SUI.

Urge Urinary Incontinence (UUI): In UUI, urine leakage is due to involuntary contractions of the bladder. ${ }^{10}$ Commonly referred to as "overactive bladder," this incontinence is usually caused by involuntary contractions of the detrusor muscles of the bladder wall at inappropriate times. There is no gradual build-up of desire to urinate in this type of incontinence and a large amount of urine is lost during each incontinence episode. ${ }^{14}$ Urge Urinary Incontinence may be triggered by simple everyday occurrences such as the sound of running water, exposure to cold temperatures, or drinking cold beverages. A classic example of a trigger is the notorious "Key in the lock" syndrome. Women are able to hold their urine until they get home, but when they insert the key in their door the urine just pours out beyond their control. ${ }^{10}$

1. Anatomical factors such as bladder outlet obstruction, pelvic masses, urethral diverticulum, or pregnancy play a key role.

2. Bladder inflammation, urinary tract infections, urinary stones, bladder cancer could cause UUI.

3. Behavioral factors like excess fluid and caffeine intake, habitual increased voiding frequency, and obsessive anxiety about urinary problems have a significant effect.

4. Chronic medical conditions like diabetes, multiple sclerosis, Parkinson's disease, brain tumors, other neurological diseases, and spinal cord injury also contribute to Urge Urinary Incontinence.

5. Idiopathic etiologic factors include myogenic, neurogenic and urethrogenic manifestations.

Mixed Urinary Incontinence (MI): The bladder is overactive and the urethra and urethral sphincter muscles are underactive or deficient. ${ }^{14}$ Etiologic factors for mixed urinary incontinence are a combination of the factors described for stress and urge urinary incontinence. ${ }^{10}$

\section{GENERAL ASSESSMENT OF UI:}

A. Initial Evaluation: The initial evaluation of patients with incontinence requires a systematic approach to consider the probable causes.

1. History: A thorough medical history should be obtained from every incontinent patient.

2. Physical examination: The physical examination of the patient with incontinence should focus on both the general medical conditions that may affect the lower urinary tract as well as the problems related to urinary incontinence. $^{17}$

3. Simple primary care tests: Simple primary care clinical tests are an integral part of initial evaluation. $^{18}$

4. Voiding diary: A frequency volume bladder 
chart (bladder diary) is an invaluable aid in the evaluation of patient with urinary incontinence. $^{19}$

5. Systemic examination: Gait assessment should be done and mobility status should be noted. A detailed neurological examination should incorporate measures of mental status, perineal sensation, perineal reflexes and patellar reflexes. $^{20}$

6. Pelvic examination: It should be done with full bladder. Degree of pelvic relaxation with cystocele or cystourethrocele should be noted. The examination tests are stress test, pad test and Q-tip test. Levator ani muscle symmetry should be noted during the ability to squeeze test. Anal sphincter function, presence of fissures and symmetry during squeezing should be noted. ${ }^{16}$

B. Urodynamic Studies: Urodynamic studies are a means of evaluating pressure flow relationship between bladder and urethra. The following form an integral part of urodynamic assessment: ${ }^{16}$

1. Uroflowmetry

2. Cystometry: Single channel \& multichannel cystometrography

3. Post void residual (PVR) urine volume

4. Urethral pressure profiles for urethral closure pressures

5. Leak Point Pressure (LPP) measurement

6. Neurophysiologic studies.

\section{TREATMENT OF UI:}

A. Conservative treatment:

1. Behavior modifications such as weight loss, smoking cessation, timed voiding, and watching caffeine and excess fluid intake useful in treatment of SUI and UUI. ${ }^{21}$

2. Pelvic floor muscle training in order to strengthen the pelvic floor muscles that provide support to the urethra play a significant role in the treatment of SUI and UUI. ${ }^{22}$

3. Vaginal devices (pessaries) and urethral inserts are available for treating SUI. ${ }^{23}$

4. Pharmacological therapy: Anti-muscarinic drugs are widely used in the management of UUI. $^{10}$

B. Surgical treatment:

1. Mid-urethral sling procedures: useful in treatment of SUI, where there is a synthetic mesh inserted vaginally in order to provide support to the urethra.

2. Augmentation cystoplasty, Auto augmentation, and Sacral nerve stimulation aimed at treating UUI. $^{10}$

C. Treatment for Mixed Urinary Incontinence needs to be undertaken in two steps. First, the most bothersome component of urinary incontinence must be identified and treated satisfactorily, and then the second component may be addressed. ${ }^{24}$

\section{METHODOLOGY}

Type of Study: Cross-sectional study

Study Design: Observational

Study Population: All females above 18 years of age attending the hospital OPD of Homoeopathy University, Saipura, Sanganer, Jaipur.

Study Setting: Out-patient Department (OPD) of the Hospital attached with Homoeopathy University, Saipura, Sanganer, Jaipur, Rajasthan, India.

Study Duration: Study conducted for three months after approval of the proposal.

Sample Size: $320 \pm 10$. [For estimation of sample size, prevalence of urinary incontinence was taken as $21.8 \%$ as per Indian journal of urology. Level of confidence $(Z)$ is $95 \%(1.96)$ and precision $(d)$ is 0.05 (because $P$ is between 0.1 and 0.9 ); so, $n=322.56]$.

Selection criteria:

- Inclusion criteria: Females above 18 years of age and gave consent to participate in study were included.

- Exclusion criteria: Pregnant females and females who were in postpartum period (upto 6weeks) were excluded.

Data Collection Procedure and Instrument Used: Questionnaire for Urinary Incontinence ${ }^{2}$ (Appendix). Plan of analysis/ statistical tools ${ }^{25}$ : The $95 \%$ confidence band is the range in which the 'true' rate of the area can be expected to lie 19 times out of 20 . For this proposed prevalence study above mentioned band can be approximated from $x \pm 2 \sqrt{ } x$, where $x$ is the observed number of cases in the study.

Ethical consideration: The ethical clearance was obtained from the Institutional Ethical Committee (IEC) of Homoeopathy University, Jaipur, prior to conducting the study.

\section{OBSERVATIONS AND RESULTS}

In this study total 322 females were screened in three months, out of which 178 (55\%) females were found to be incontinent (fig: 1 ).

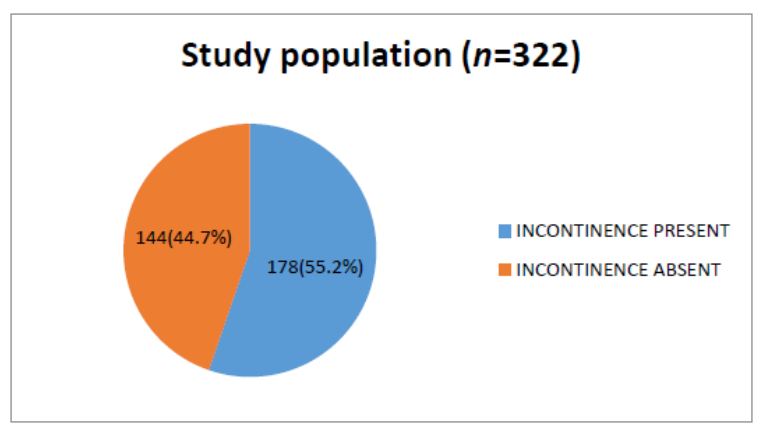


Fig: 1- Distribution of study population according to their continent status.

\section{Study population $(n=322)$}

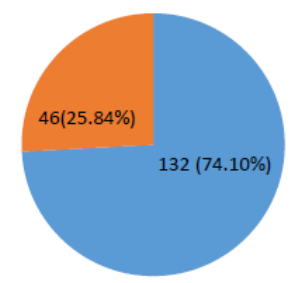

Fig: 2- Distribution of incontinent females according to type of incontinence.

The two tables $(1 \& 2)$ below are showing the observations of study population according to urinary incontinence in relation to age and parity.

Table 1: Distribution of study population according to type of incontinence in relation to age groups-

\begin{tabular}{|l|l|l|l|l|l|l|}
\hline $\begin{array}{l}\text { Age } \\
\text { group }\end{array}$ & Total & UI & SUI & MI & NONE & \\
\hline $18-32$ & 155 & $48(26.9 \%)$ & $46(25.8 \%)$ & $2(1.1 \%)$ & 107 & \\
\hline $33-48$ & 106 & $78(43.8 \%)$ & $60(33.7 \%)$ & $18(10.1 \%)$ & 28 & \\
\hline $49-77$ & 61 & $52(29.2 \%)$ & $26(14.60 \%)$ & $26(14.60 \%)$ & 9 & \\
\hline
\end{tabular}

Table 2: Distribution of study population according to type of incontinence in relation to number of parity-

\begin{tabular}{|l|l|l|l|l|c|}
\hline PARITY & Total & UI & SUI & MI & NONE \\
\hline $0-3$ & 260 & $133(74.7 \%)$ & $106(59.5 \%)$ & $27(15.1 \%)$ & 127 \\
\hline $3-8$ & 62 & $45(25.3 \%)$ & $26(14.6 \%)$ & $19(10.6 \%)$ & 17 \\
\hline
\end{tabular}

\section{Statistical Analysis:}

Table 3: Statistical analysis for prevalence of urinary incontinence (in \%) in total population, with its type (stress, mixed) at 95\% confidence level-

\begin{tabular}{|l|l|l|}
\hline & $\mathbf{Z}$-test & Confidence interval \\
\hline Total population & $55.3 \%(178 / 322)$ & $50 \%$ to $60 \%(0.5032-0.603)$ \\
\hline SUI & $72.5 \%(129 / 178)$ & $66 \%$ to $79 \%(0.659-0.79)$ \\
\hline MI & $27.5 \%(49 / 178)$ & $21 \%$ to $34 \%(0.21-0.341)$ \\
\hline
\end{tabular}

The above statistical test has shown a higher prevalence of urinary incontinence in women with SUI (66-79\%) occurrence in comparison to MI. The UUI could not be separately calculated as it was found that the occurrence of UUI is necessarily associated with SUI.

Table 4: Statistical analysis for association of UI with age and parity in total population, with its type (stress, mixed) at $95 \%$ confidence level-

\begin{tabular}{|l|l|l|}
\hline Type of variable & Chi square & $\boldsymbol{p}$ value \\
\hline Age & 60.802 & 0.000 \\
\hline
\end{tabular}

\begin{tabular}{|l|l|l|}
\hline Parity & 9.297 & 0.002 \\
\hline
\end{tabular}

There is a significant difference in the prevalence of stress urinary incontinence among women of reproductive age in comparison with the women of non reproductive age. In reproductive age group, older age group women are more prone to UI than the younger age group, which is significant by cross tabulation (tables $1 \& 2$ ).

This finding also matches with the cross tabulation of age and incontinence, therefore stress urinary incontinence is higher among women who are in reproductive age in comparison with non reproductive age.

It is evident from the cross tabulation of parity and incontinence that the prevalence of incontinence is higher among woman who have parity upto three in comparison with those women who have parity more than three.

There is a significant association in parity and UI. Chi-square value (9.297) shows significant difference between lower parity, higher parity and prevalence of incontinence with $p$ value 0.002 . It is clearly evident that prevalence of incontinence is higher among women whose parity is three or less in comparison with more than three.

\section{DISCUSSION}

This study was conducted with the aim to know the prevalence of urinary incontinence according to age, parity and type of incontinence in females above 18 years of age.

In present study, out of 322 females, 178 (55.2\%) females reported urinary incontinence. This result is different from the hospital based survey at Lucknow done by Uma Singh et $\mathrm{al}^{2}$ which showed $21.8 \%$ prevalence of UI out of 3000 women in a period of 2 years.

In this study, stress incontinence was found to be highest $(74.1 \%)$ followed by prevalence of mixed $(25.84 \%)$ incontinence. This was similar to the study of Chaandini ${ }^{10}$ in which SUI $(43 \%)$ was the commonest type followed by MI (25\%).

In present study pure SUI was found frequently in both age groups of 18-32 years and 33-48 years and decreasing in the older age groups; mixed urinary incontinence (SUI and UUI) was consistently found in females older than 33 years. These results are comparable to the study of Uma Singh ${ }^{2}$ that stated all types of urinary incontinence were found to be significantly higher among women above 40 years of age.

It is observed that maximum $(99 \%)$ incontinent females assessed under this study were parous. Uma Singh $^{2}$ and Abha Choudhary ${ }^{4}$ stated in their studies that pregnancy and child birth are regarded as key environmental determinants of urinary incontinence and more than $60 \%$ of incontinent women associate 
its onset with pregnancy, child birth or postpartum. In present study, SUI was most frequently found in women of lower parity and as the parity increases, the SUI mixes with UUI. According to Uma Singh ${ }^{2}$ incontinence was found to be positively associated with increasing parity. Differentially stress incontinence showed an increasing trend with increasing parity; however, in case of urge incontinence, prevalence was high only in grand multiparous women.

Limitation of the study: Females were not willing to detail her incontinence symptoms. It was difficult to obtain clear picture of the disease because of their hesitation.

\section{CONCLUSION}

Urinary incontinence has an impact on the quality of life and affects productivity and decreases activity levels in women. The study also signifies that in our society how neglected is women's health particularly genitourinary health?

The results of this study have led us to conclude that prevalence of UI in females is very common (55.2\%) in comparison to their continent peers. Stress Urinary Incontinence $(74.1 \%)$ is more prevalent than any other type of urinary incontinence.

In younger age group, stress urinary incontinence was more prevalent (more than $84 \%$ ) than mixed. In the older women, the type of incontinence become mixed with urge urinary Incontinence.

According to parous level of women, stress urinary incontinence is much more prevalent (about 80\%) in women of lower parity; as parity increases stress urinary incontinence become mixed with urge urinary Incontinence.

Implication: The prevalence of urinary incontinence among women is of concern and needs to be addressed appropriately. Treating urinary incontinence appropriately would greatly improve the quality of life of females suffering from this problem.

\section{APPENDIX}

Questionnaire for Urinary Incontinence ${ }^{2}$

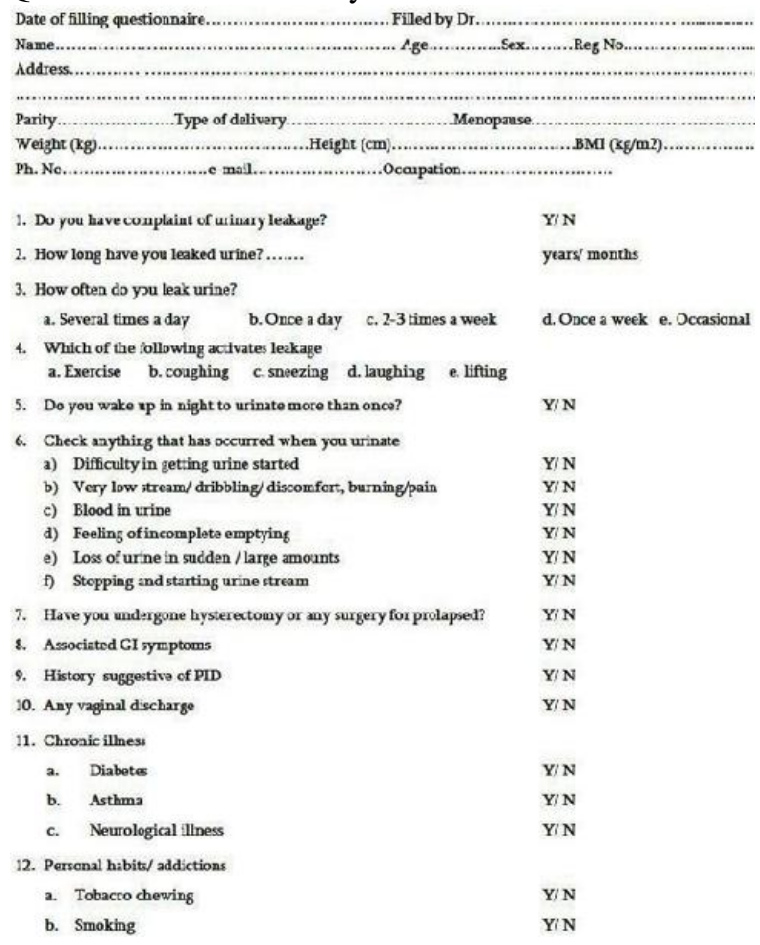

\section{ACKNOWLEDGEMENT}

We sincerely acknowledge the administrative and teaching faculty of Homoeopathy University, Jaipur, Rajasthan, India, and staff of Dr. Girendra Pal Homoeopathic Hospital \& Research Centre, Jaipur, for providing a conducive environment and moral support to accomplish this project.

\section{REFERENCES}

1. Abrams P, Cardozo L, Fall M. The Standardization of terminology of lower urinary tract function: report from the standardization sub-committee of the International Continence Society. Urology 2003; 61:37-49.

2. Singh U, Agarwal P, Verma M. Prevalence and risk factors of urinary incontinence in Indian women: A hospital-based survey. Indian journal of urology 2013 Jan-Mar; 29(1):31-36.

3. Markland A, Richter H, Eggers P, Kusek J. Prevalence and Trends of Urinary Incontinence in Adults in the United States, 2001 to 2008. Journal of Urology 2011;186(2):589-593.

4. Choudhary A, Dadhich R. Prevalence of Different Types of Urinary Incontinence and their Association with Age and Parity. Indian Journal of Urology 2018 Apr;6(4):2455-0450.

5. Diokno AC. Incidence and prevalence of stress urinary incontinence [Internet]. 2003 Sep [updated 2003 Sep; cited 2019 May 19]. Available from: https://pdfs.semanticscholar.org/e35d/b9356506 
c6e22494d32cc6ff84fc4e5cdbc3.pdf

6. Sensoy N, Dogan N, Ozek B, Karaaslan L. Urinary incontinence in women: prevalence rates, risk factors and impact on quality of life [serial online]. 2013 [cited 2019 May 18]; 29(3): 818- 822. Available from: https://www.ncbi.nlm.nih.gov/pmc/articles/PM C3809317/

7. Townsend MK, Curhan GC, Resnick NM, Grodstein F. The incidence of urinary incontinence across Asian, black, and white women in the United States. Am J Obstet Gynecol. 2010;202(4):1-7.

8. Minassian VA, Drutz HP, Al-Badr A. Urinary incontinence as a worldwide problem. Int $\mathrm{J}$ Gynaecol Obstet. 2003;82(3):327-338.

9. Kocak I, Okyay P, Dundar M, Erol H, Beser E. Female urinary incontinence in the west of Turkey: prevalence, risk factors and impact on quality of life. Eur Urol. 2005;48(4):634-641.

10. Jayachandran C. Prevalence of Stress, Urge, and Mixed Urinary Incontinence in Women Eastern Michigan University [Internet].2007 [cited 2007 March 9]. Available from: http://commons.emich.edu/theses

11. Medical Definition of Incontinence of Urine [Internet]. 2018 Jul 9 [cited 2019 May 18]. Available from: https://www.medicinenet.com/script/main/art.as p?articlekey $=3960$

12. Nygaard IE, Heit M. Stress urinary incontinence. ObsteGynecol. 2004;104:607620.

13. Rockville. Clinical Guidelines: Urinary Incontinence in Adult.The American journal of nursing, 1992 Oct;92:75-93.

14. Berek JS. Berek and Novak's Gynecology. $15^{\text {th }}$ ed. New Delhi: Wolters Kluwer India Pvt Ltd; 2016. p. 865-902.

15. Haylen BT, de Ridder D, Freeman RM. An International Urogynecological Association (IUGA)/International Continence Society (ICS) joint report on the terminology for female pelvic floor dysfunction. Neurourol Urodyn. 2010;29:4-20.

16. Sharma N, Chakrabarti S. Clinical evaluation of urinary incontinence. Journal of Mid-life Health
2018;9(2):55.

17. Lucas MG, Bosch RJ, Burkhard FC, Cruz F, Madden TB, Nambiar AK, et al. EAU guidelines on surgical treatment of urinary incontinence. Eur Urol. 2012; 62:1118-29.

18. Goldman HB, Wyndaele JJ, Kaplan SA, Wang JT, Ntanios F. Defining response and nonresponse to treatment in patients with overactive bladder: A systematic review. Curr Med Res Opin. 2014; 30:509-26.

19. Homma Y, Kakizaki H, Yamaguchi O, Yamanishi T, Nishizawa O, Yokoyama O, et al. Assessment of overactive bladder symptoms: Comparison of 3-day bladder diary and the overactive bladder symptoms score. Urology 2011; 77:60-4.

20. Apostolidis A, Kirana PS, Chiu G, Link C, Tsiouprou M, Hatzichristou D, et al. Gender and age differences in the perception of bother and health care seeking for lower urinary tract symptoms: Results from the hospitalised and outpatients' profile and expectations study. Eur Urol. 2009; 56:937-47.

21. Hay smith J, Berghman B, Burgio K, et al. Adult conservative management [Internet]. 2019 [cited 2019 May 19]. Available from: https://www.ics.org/Publications/ICI_4/filesbook/comite-12.pdf

22. Dumoulin C, Hay smith J. Pelvic floor muscle training versus no treatment, or inactive control treatment, for urinary incontinence in women. Cochrane Database of Systematic Reviews [Internet]. 2010 [cited 2019 may 19]. Available from: https://www.ncbi.nlm.nih.gov/pubmed/ 24823491.

23. Donnelly MJ, Powell-Morgan S, Oslenal, et al. Vaginal pessaries for management of stress and mixed urinary incontinence. Int Urogynecol J Pelvic floor dysfunction. 2004;15:302-307.

24. Dmochowski R. Urinary Incontinence: Proper Assessment and Available Treatment Options. J Women's Health. 2005; 14(10): 906-916.

25. Naing L, Winn T, Rusli BN. Practical Issues in Calculating the Sample Size for Prevalence Studies. Archives of Orofacial Sciences 2006; 1: 9-14. 